\section{CALLING ALL PRIMARY CARE PRACTITIONERS: PROMOTING ORGAN AND TISSUE DONATION}

A little over two years ago, I was fortunate enough to act as a living liver donor to an 11-month old infant in need of a transplant. While I have always been a firm believer in organ and tissue donation, the process of becoming a donor myself truly opened my eyes to the dire need for improvement within the realm of organ and tissue donation in Canada. In the time since, I have been able to research the topic in greater depth, and have come to realize, as many others have, that the answer to the organ/tissue shortage across the country is multifaceted, and as with everything, changes can, and must be made from the level of primary care upwards if we hope to succeed.

The good news is that there are a number of initiatives currently being implemented throughout the country. This past August, it was announced that a series of new national registries will be created through the work of the Canadian Council for Donation and Transplantation which has merged with Canadian Blood Services. These new registries will allow for greater inter-provincial coordination, hopefully increasing the efficient use of donor organs, both living and deceased (1). Furthermore, the acceptance of organs for donation after cardiac death has also contributed positively to the organ crisis currently being faced in Canadian healthcare.

Despite these advances however, more can be done at a primary care level. The reality is that while many of us may not personally require the services of an organ donor in the future, each of us has the potential to assist others once we have passed away. Misinformation and lack of understanding of the processes of organ and tissue donation abound in the Canadian public, and only through education can we hope to remedy this situation.

Many of the more common fallacies are very quickly and easily addressed, taking at most a few minutes of discussion to clear up any uncertainty on the part of the patient. Questions of who may donate, what can be donated, and religious viewpoints on donation are on the minds of many people, but few get the opportunity to ask these questions of their healthcare provider. In a system where the decision to donate is left up to the individual, it is imperative that people be wellinformed, so as to be able to make the right decision for themselves, based on their own opinions and beliefs.

It is for these reasons that I call upon every primary care practitioner (present and future), be they family doctors, nurse practitioners, or otherwise, to at the very least address the topic of organ and tissue donation with their patients. Below are a few examples of how the topic can be quickly and easily broached with a large number of patients.

Firstly, a brief section addressing the patient's wishes regarding organ and tissue donation can easily be added to a new patient intake form. With every new patient coming into your practice, a thorough medical history is always taken, and a few simple questions during the course of this first visit could easily identify the patient's familiarity with the subject, as well as discern their current views on the topic.

The same idea can be applied to existing patients by adding a few select questions to any existing "routine physical" information sheet. While these brief encounters may not lead the patient to immediately go out and sign a donor card (if they haven't already done so), at the very least they may stimulate some thought, and research on the part of the patient.

Finally, an extremely simple way of increasing awareness of organ and tissue donation within your patient population is to have reading materials such as pamphlets and donor cards, available for use in your waiting rooms. Not only will this be of interest to some of your patients, but it will also ensure that these informational aids are available for you to dispense to any patients that have expressed interest in the subject through the course of your discussion/interaction with them. All of these materials are available free of charge from your provincial organ and tissue donation body.

Each of these measures is simple enough that it could easily be adapted into any practice model, while concurrently enhancing patient education on a very relevant and important topic. In the world of organ and tissue donation the old adage of "every little bit helps" is completely true, and it is my sincerest hope that those of you reading this article will at the very least be more conscious of the subject within your practice. The harsh reality is that on December 31,2007, there were 4,195 Canadians on wait-lists for organ transplants (1), and many more who would be able to benefit from tissue donations.

As someone who has seen first-hand the incredible benefits of organ transplantation, I implore you to help 
promote this life-saving process to your patients, and in turn help to alleviate the disheartening wait-lists across Canada.

Sincerely,

Mike Ballantine

Schulich School of Medicine and Dentistry

University of Western Ontario

mballantine2011@meds.uwo.ca

\section{REFERENCES}

1. Canadian Council for Donation and Transplantation. (2008). News release Tuesday August 12, 2008; Organ donation and transplantation streamlined in new national system: patient/donor registries and $\$ 35$ million in new funding will save lives. Retrieved September 28, 2008, from http://www.ccdt.ca/english/home.html

2. Gill, J.S., Klarenbach, S., Cole, E., \& Shemie, S.D. (2008).

Deceased organ donation in Canada: an opportunity to heal a fractured system. American Journal of Transplantation, $8,1580-1587$.

Mike Ballantine is a 3rd year medical student at the Schulich School of Medicine and Dentistry, in London, Ontario. He is primarily interested in emergency medicine, but remains dedicated to organ donation awareness as well. 